\title{
EFFECTS OF SUPER ABSORBENT POLYMER ON THE PHYSIOLOGICAL CHARACTERISTICS AND DROUGHT RESISTANCE OF BERMUDAGRASS [CYNODON DACTYLON (L.) PERS.] SEEDLINGS
}

\author{
CAO, Y. $.^{1,2^{*}}-$ XIE, Q $.^{1 *}-$ WANG, J. ${ }^{1}-$ YANG, J. ${ }^{1}-$ XIE, Z. ${ }^{1,2}$ \\ ${ }^{1}$ College of Geography and Environment, Jiangxi Normal University, Nanchang 330022, PR \\ China \\ ${ }^{2}$ Key Laboratory of Poyang Lake Wetland and Watershed Research, Ministry of Education, \\ Jiangxi Normal University, Nanchang 330022, PR China \\ *Corresponding authors \\ e-mail:yun.cao@163.com,2829364804@qq.com
}

(Received 6 ${ }^{\text {th }}$ Jan 2020; accepted $24^{\text {th }}$ Mar 2020)

\begin{abstract}
Cynodon dactylon (L.) Pers. seedlings was used as test material and applied five SAP concentrations: $0.00 \%, 0.10 \%, 0.20 \%, 0.30 \%$, and $0.40 \%$. The effects of the five SAP treatments on the physiological characteristics of $C$. dactylon seedlings under two water supply conditions were studied and a comprehensive drought resistance evaluation method was used to analyze and evaluate the drought resistance of $C$. dactylon. Results: (1) the concentrations of photosynthetic pigments, including Chlorophyll a, Chlorophyll b, and Chlorophyll $\mathrm{a}+\mathrm{b}$ were all higher than those in the CK group when the SAP concentration was $0.10 \%-0.30 \%$; (2) The malondialdehyde, superoxide dismutase, peroxidase, and catalase activities in the leaves of $C$. dactylon treated with SAP were all altered, and the concentrations of MDA were higher than those in the CK group, indicating that applying SAP could minimize the environmental stress experienced by $C$. dactylon. (3) The addition of SAP could improve the drought resistance of $C$. dactylon seedlings. Under adequate water conditions, the order of drought resistance of $C$. dactylon under the five SAP concentrations would be $0.30 \%>0.10 \%>0.20 \%>0.40 \%>0.00 \%$, and under limited water conditions, the order would be $0.20 \%>0.30 \%>0.40 \%>0.10 \%>0.00 \%$.

Keywords: super absorbent polymer concentrations, Cynodon dactylon, (L.) Pers, physiological ecological characteristics, evaluation of drought resistance, under adequate and limited water supply

Abbreviations: SAP: super absorbent polymer; C. dactylon: Cynodon dactylon, (L.) Pers; SOD: superoxide dismutase $\left(\mathrm{U} \cdot \mathrm{g}^{-1}\right)$; POD: peroxidase $\left(\mathrm{U} \cdot\left(\mathrm{g} \cdot \mathrm{min}^{-1}\right)\right)$; CAT: catalase $\left(\mathrm{U} \cdot \mathrm{g}^{-1}\right)$; MDA: malondialdehyde (nmol $\left.\cdot \mathrm{g}^{-1}\right)$; Chl-a: chlorophyll a $\left(\mathrm{mg} \cdot \mathrm{g}^{-1}\right)$; Chl-b: chlorophyll b $\left(\mathrm{mg} \cdot \mathrm{g}^{-1}\right)$; Chl a+b: the total chlorophyll content $\left(\mathrm{mg} \cdot \mathrm{g}^{-1}\right)$; Chla/b: chlorophyll $\mathrm{a} / \mathrm{b}\left(\mathrm{mg} \cdot \mathrm{g}^{-1}\right)$; Car: carotenoid $\left(\mathrm{mg} \cdot \mathrm{g}^{-1}\right)$
\end{abstract}

\section{Introduction}

Cynodon dactylon (L.) Pers., which is widely distributed globally but occurs predominantly in tropical and warm temperate regions (Zeng and Li, 2019; Hameed et al., 2008), is a perennial herb in the genus Eragrostoideae Pilger (Jayanthi et al., 2016). Because of its low height, strong breeding capacity, and drought, salinity, and heavy metal resistance (Archer and Caldwell, 2004; Kim et al., 2009; Hameed et al., 2008; Xie et al., 2016), it is widely used in soil and water conservation (Srivastava and Singh, 2012), ecological restoration, and green building (Singh et al., 2013; Leung et al., 2015). In China, $C$. dactylon is distributed in areas with varying rainfall from the north to the south. Moisture conditions influence plant survival and growth, and excessive water or drought would affect plant morphology and physiology (Hu et al., 2014). 
Super absorbent polymer (SAP) is a safe and harmless polymer compound (Suresh et al., 2018). It can absorb and hold water weighing more than a hundred or even a thousand times its own weight (Zohuriaan-Mehr and Kabiri, 2008). Therefore, it could be used to improve soil structure, enhance soil water retention, reduce soil moisture loss, improve the emergence rates of plants and drought tolerance (Arbona et al., 2005; Yang et al., 2014), and promote aboveground and belowground growth (Islam, et al., 2011). Appropriate SAP concentration selection is very critical. A too low dosage would not achieve the desired effects, while a too high dosage would affect soil permeability severely (Li et al., 2019), which would, in turn, result in respiration challenges or even root rot.

In recent years, numerous studies have explored the effects of SAP on agricultural applications, soil properties, plant growth and physiology, and its influence on plant production (Fernando et al., 2017; Tongo et al., 2014; Karimi et al., 2009; Wu et al., 2018). However, studies on the physiological characteristics of $C$. dactylon under different SAP concentrations and moisture conditions have not been conducted. And whether the application of SAP to $C$. dactylon can also promote the development of aboveground part and root system is less studied. Therefore, the present study, five SAP concentrations $(0.00 \%, 0.10 \%, 0.20 \%, 0.30 \%$, and $0.40 \%)$ were applied to soil under two moisture conditions (adequate and limited water supply) to investigated the effects of SAP on the physiological characteristics and drought resistance of $C$. dactylon seedlings under different water availability. In addition, we explore the optimal SAP concentrations for the growth of $C$. dactylon, which could offer a theoretical basis for the application of SAP in the production and exploitation of $C$. dactylon.

\section{Materials and methods}

\section{Experimental design}

The experiments used SAP manufactured by Henan God biological science and technology, which exhibits the highest water holding capacity, at 300-500 times the SAP weight. The experimental matrices were mixed at a 1:1:1 volume ratio, and the soil, sand, and straw ash in their natural states were mixed in an experimental basin with a height of $13 \mathrm{~cm}$, a length of $35 \mathrm{~cm}$, and a width of $26 \mathrm{~cm}$, and the weight of each substrate was $8 \pm 0.5 \mathrm{~kg}$. The concentration of SAP was mixed with the test substrate based on mass ratios of $0.00 \%$ (the CK group), $0.10 \%, 0.20 \%, 0.30 \%$, and $0.40 \%$. Before planting $C$. dactylon stolons, they were processed into $1-3 \mathrm{~cm}$ ( 2 buds) segments, placed in a basin filled with distilled water, soaked for $0.5 \mathrm{~h}$, seeded by layering every pot planting 30 segment, covering $1 \mathrm{~cm}$, dealing with repeated 3 times in each group. The experiments were carried out from March to May 2016 in a sun culture room at the Key Laboratory of Poyang Lake Wetland and Watershed Research, Ministry of Education, Nanchang, Jiangxi, China, lasted for 60 days. Water treatments were divided into a limited water supply group and an adequate water supply group. In the limited water supply group, the plants were watered with $150 \mathrm{ml}$ every 20 days, while in the adequate water supply group, the plants were watered with $150 \mathrm{ml}$ every 4 days. The soil moisture concentrations in the two treatment groups were measured using a HH2 soil moisture meter (Delta-T, Burwell, Cambridge, UK) every 3 days. The average soil moisture concentrations in the two groups were $28.5 \pm 3 \%$ and $10.5 \pm 5 \%$. 


\section{Determination of physiological indices of seedlings}

At the end of the experiments, the seedlings were harvested from the pots, washed with distilled water, and dried. The fresh plant leaves were collected to measure the physiological indices of the seedlings. The physiological indices were determined according to Wang (2006). Chlorophyll concentrations and Carotenoid (Car) concentrations were determined following extraction with $95 \%$ ethanol and spectrophotometry. Superoxide dismutase (SOD) concentrations were determined using the nitrogen blue tetrazolium method, while peroxidase (POD) concentrations was determined by measuring guaiacol peroxidase activity using guaiacol. Catalase (CAT) concentrations were determined using the potassium permanganate titration method, and malondialdehyde (MDA) concentrations were measured using the thiobarbituric acid method (Wang., 2006).

\section{Comprehensive evaluation of drought resistance}

Analysis of drought resistance in $C$. dactylon was based on the measured physiological indicators. Principal component analysis was adopted for performing dimensionality reductions on the original indices, and Equation 3 was used to determine the percentages of each factor. Subsequently, Equations 1, 2, and 4 were used for the evaluation of each synthetic index of drought resistance, in addition to SOD, POD, and MDA in the anti-subordinate function analysis, the remaining indexes using the method of subordinate function. Eventually let every comprehensive index can represent the difference basically between the original.

(1) Membership function analysis (Wang et al., 2013):

Membership function values:

$$
\mathrm{R}\left(\mathrm{X}_{\mathrm{i}}\right)=\left(\mathrm{X}_{\mathrm{i}}-\mathrm{X}_{\min }\right) /\left(\mathrm{X}_{\max }-\mathrm{X}_{\min }\right)
$$

Anti-membership function values:

$$
\mathrm{R}\left(\mathrm{X}_{\mathrm{i}}\right)=1-\left(\mathrm{X}_{\mathrm{i}}-\mathrm{X}_{\min }\right) /\left(\mathrm{X}_{\max }-\mathrm{X}_{\min }\right)
$$

Where $X_{i}$ is the index value, and $X_{\min }$ and $X_{\max }$ are the minimum and maximum values of any indices of the test materials.

(2) Weight calculation:

$$
\boldsymbol{W}_{\boldsymbol{i}}=\frac{\boldsymbol{P}_{\boldsymbol{i}}}{\sum_{i=1}^{\boldsymbol{n}} \boldsymbol{P}_{\boldsymbol{i}}} \mathrm{i}=1,2, \ldots \mathrm{n}
$$

Where $\mathrm{W}_{\mathrm{i}}$ is the important degree of the ith comprehensive index in all indices, and $\mathrm{P}_{\mathrm{i}}$ is the contribution rate of the ith comprehensive index.

(3) Evaluation of drought resistance:

$$
D=\sum_{i=1}^{n}\left[R\left(X_{i}\right) \times W_{i}\right] \mathrm{i}=1,2, \ldots \mathrm{n}
$$


Where $\mathrm{D}$ value is the comprehensive evaluation value of plant drought resistance calculated at the concentration of different super absorbent polymer concentrations.

\section{Statistics analysis}

Data analysis was completed by MS Excel 2010 (Microsoft Corp., Redmond, WA, USA) and IBM SPSS Statistics 21.0 (IBM Corp., Armonk, NY, USA). The effects of different SAP treatments on physiological ecological characteristics of $C$. dactylon seedlings were analyzed using one-way analysis of variance, and the differences between indices in different groups were tested using the least significant difference test.

\section{Results}

\section{Effects of different SAP concentrations on chlorophyll concentration in C. dactylon leaves}

The concentrations of chlorophyll a (Chl-a), chlorophyll b (Chl-b), chlorophyll $a+b$ $(\mathrm{Chl} \mathrm{a}+\mathrm{b})$, and carotenoid (Car) increased significantly after the application of reasonable concentrations of SAP under the two water conditions. Under the adequate water supply condition, the concentrations of Chl-a $\left(10.646 \sim 11.704 \mathrm{mg} \cdot \mathrm{g}^{-1}\right)$ and Chl-b (4.192 4.811 $\mathrm{mg} \cdot \mathrm{g}^{-1}$ ) were significantly lower in the leaves of $C$. dactylon treated with different SAP concentrations, which were higher than the concentrations in the CK group and were the highest at the $0.30 \%$ SAP concentration. Chl-a, Chl-b, and Chla+b concentrations increased by $22.41 \%, 22.09 \%$, and $23.74 \%$, respectively. In addition, the Car concentration at the $0.40 \%$ SAP concentration $\left(1.767 \mathrm{mg} \cdot \mathrm{g}^{-1}\right)$ was the highest increased compared to the CK group $\left(0.990 \mathrm{mg} \cdot \mathrm{g}^{-1}\right)$, which represented a $43.95 \%$ increase. Under limited water conditions, the concentrations of Chl-a, Chl-b, Chl a+b, and Car first increased and then decreased with an increase in SAP concentration. When the SAP concentrations were $0.20 \%-0.30 \%$, the concentrations of all the indices were higher than in the $\mathrm{CK}$ group. The concentrations of Chl-a, Chl-b, and $\mathrm{Chl} \mathrm{a}+\mathrm{b}$ were the highest at the $0.20 \%$ SAP concentration, which represented $15.53 \%, 10.31 \%$, and $14.08 \%$ increases, respectively. However, the Car concentrations in all the treatment groups were the highest at the $0.30 \%$ SAP concentration $\left(2.001 \mathrm{mg} \cdot \mathrm{g}^{-1}\right)$, compared with the CK group (1.567 $\left.\mathrm{mg} \cdot \mathrm{g}^{-1}\right)$, which represented a $21.71 \%$ increase compared to the CK group.

Under the adequate water supply and the limited water supply conditions, the chlorophyll $\mathrm{a} / \mathrm{b}$ concentrations between the treatment groups treated with SAP varied minimally. However, with an increase in SAP concentration, chlorophyll a/b content of sufficient water supply $\left(2.449 \sim 2.593 \mathrm{mg} \cdot \mathrm{g}^{-1}\right)$ and limited water supply $(2.497 \sim 2.649$ $\mathrm{mg} \cdot \mathrm{g}^{-1}$ ) are both higher than CK group (2.360 and $\left.2.451 \mathrm{mg} \cdot \mathrm{g}^{-1}\right)$. Compared to the CK group, the chlorophyll $\mathrm{a} / \mathrm{b}$ concentrations in the adequate water supply treatment group increased by $3.63 \%, 7.06 \%, 2.98 \%$, and $8.96 \%$, under the $0.10 \%, 0.20 \%, 0.30 \%$, and $0.40 \%$ SAP concentrations, respectively. The greatest increase was an increase of $8.96 \%$, under the $0.4 \%$ SAP concentration. In the limited water supply treatment groups, chlorophyll $\mathrm{a} / \mathrm{b}$ concentrations increased by $1.81 \%, 5.82 \%, 7.44 \%$ and $5.25 \%$, under the $0.10 \%$, $0.20 \%, 0.30 \%$, and $0.40 \%$ SAP concentrations, respectively, with the maximum increase observed under the $0.30 \%$ SAP concentration, which was $7.44 \%$. According to the results, the increase of the chlorophyll $\mathrm{a} / \mathrm{b}$ concentrations in the leaves of the seedlings was not obvious by applying SAP under the two moisture conditions (Table 1). 
Table 1. Effects of SAP on chlorophyll concentration in C. dactylon leaves $\left(m g \cdot g^{-1}\right)$

\begin{tabular}{c|c|c|c|c|c|c|c|c|c|c}
\hline $\begin{array}{c}\text { Treatment } \\
(\%)\end{array}$ & \multicolumn{4}{|c|}{ Sufficient water supply } & \multicolumn{4}{c}{ Limited water supply } \\
\cline { 2 - 10 } & Chl-a & Chl-b & Chl a+b & Car & Chl a/b & Chl-a & Chl-b & Chl a+b & Car & Chl a/b \\
\hline CK & $8.847 \mathrm{a}$ & $3.748 \mathrm{a}$ & $12.595 \mathrm{a}$ & $0.990 \mathrm{a}$ & $2.360 \mathrm{a}$ & $11.767 \mathrm{a}$ & $4.799 \mathrm{a}$ & $16.566 \mathrm{a}$ & $1.567 \mathrm{a}$ & $2.451 \mathrm{a}$ \\
0.10 & $11.487 \mathrm{~b}$ & $4.690 \mathrm{~b}$ & $16.177 \mathrm{~b}$ & $1.376 \mathrm{~b}$ & $2.449 \mathrm{a}$ & $13.153 \mathrm{~b}$ & $5.268 \mathrm{~b}$ & $18.421 \mathrm{~b}$ & $1.920 \mathrm{~b}$ & $2.497 \mathrm{a}$ \\
0.20 & $10.646 \mathrm{c}$ & $4.192 \mathrm{c}$ & $14.838 \mathrm{c}$ & $1.526 \mathrm{~b}$ & $2.539 \mathrm{a}$ & $13.930 \mathrm{c}$ & $5.351 \mathrm{~b}$ & $19.281 \mathrm{c}$ & $1.923 \mathrm{~b}$ & $2.603 \mathrm{a}$ \\
0.30 & $11.704 \mathrm{~b}$ & $4.811 \mathrm{~b}$ & $16.515 \mathrm{~d}$ & $1.415 \mathrm{~b}$ & $2.433 \mathrm{a}$ & $12.991 \mathrm{~b}$ & $4.904 \mathrm{c}$ & $17.895 \mathrm{~d}$ & $2.001 \mathrm{~b}$ & $2.649 \mathrm{a}$ \\
0.40 & $10.904 \mathrm{c}$ & $4.206 \mathrm{c}$ & $15.110 \mathrm{e}$ & $1.767 \mathrm{c}$ & $2.593 \mathrm{a}$ & $11.388 \mathrm{~d}$ & $4.401 \mathrm{~d}$ & $15.788 \mathrm{e}$ & $1.749 \mathrm{ab}$ & $2.588 \mathrm{a}$ \\
\hline
\end{tabular}

The letters represent the differences within the group. The same letters represent no differences. The different letters represent differences $(\mathrm{p}<0.05)$

\section{Effects of different SAP concentrations on C. dactylon leaf enzyme activity}

The concentrations of SOD and POD in the leaves of $C$. dactylon were significantly lower than those in the CK group, and CAT concentrations were higher than those in the CK group under the two moisture conditions. There were differences in the change range of each enzyme activity index. Under the adequate water supply condition, the concentrations of SOD in each group were relatively low, ranging from 146.48 to $156.72 \mathrm{U} \cdot \mathrm{g}^{-1}$, and the lowest value was observed at the $0.30 \%$ SAP concentration treatment, which was a $16.67 \%$ decrease compared to the CK. In addition, the concentrations of POD in the leaves of $C$. dactylon varied considerably, and the values in each group ranged between 20.67 and $53.34 \mathrm{U} \cdot\left(\mathrm{g} \cdot \mathrm{min}^{-1}\right)$. In the treatment group with the $0.30 \%$ SAP concentration, the POD concentration was $75.60 \%$ lower than the concentration in the CK group. In addition, CAT activity was higher than in the CK group, with the highest value observed under the $0.30 \%$ SAP concentration, which was a $67.42 \%$ increase compared to the value in the CK group.

Under the limited water supply condition, the concentrations of SOD and POD decreased with an increase of the concentration of SAP, and the lowest values were observed under the $0.40 \%$ SAP concentration, which were $21.36 \%$ and $46.61 \%$ lower, respectively, than the concentration in the CK group. CAT activity was higher than in the CK group, with the highest value observed under the $0.40 \%$ SAP concentration, which a $78.55 \%$ increase compared to the value was observed in the CK group (Fig. 1).

\section{Effects of different SAP concentrations on MDA content in C. dactylon leaves}

Under water stress conditions, plants will increase MDA concentrations, which could have toxic effects on cell membranes. Under both moisture conditions, the changes in MDA concentrations in each group were lower than the changes in the CK group under the different SAP concentrations. Under adequate water supply, with an increase in the concentrations of the water-absorbing agent, MDA concentrations decreased by $25.77 \%$, $29.36 \%, 11.67 \%$, and $8.69 \%$, under $0.10 \%, 0.20 \%, 0.30 \%$, and $0.40 \%$ SAP concentrations, respectively, compared to those in the CK group. The lowest value was observed under the $0.20 \%$ SAP concentration.

Under the limited water supply conditions, the MDA concentrations in the $0.10 \%$, $0.20 \%, 0.30 \%$, and $0.40 \%$ treatments decreased by $8.84 \%, 12.34 \%, 9.05 \%$ and $27.96 \%$, respectively, compared to the CK group. In addition, the lowest MDA concentration was observed under the $0.40 \%$ SAP concentration. According to the results, the application of SAP could reduce the degree of stress on $C$. dactylon to minimize the accumulation of MDA, and, in turn, minimize potential cell membrane damage (Fig. 2). 
a

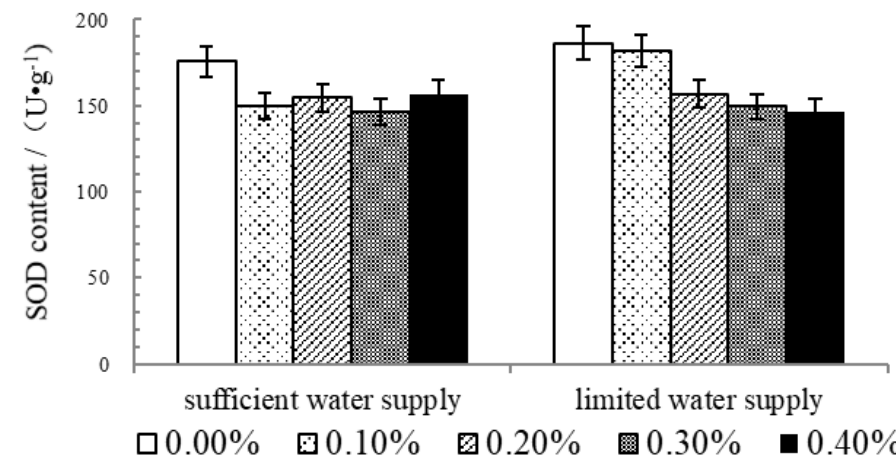

a: Effect of SAP on SOD in C. dactylon leaves

$\mathrm{b}$

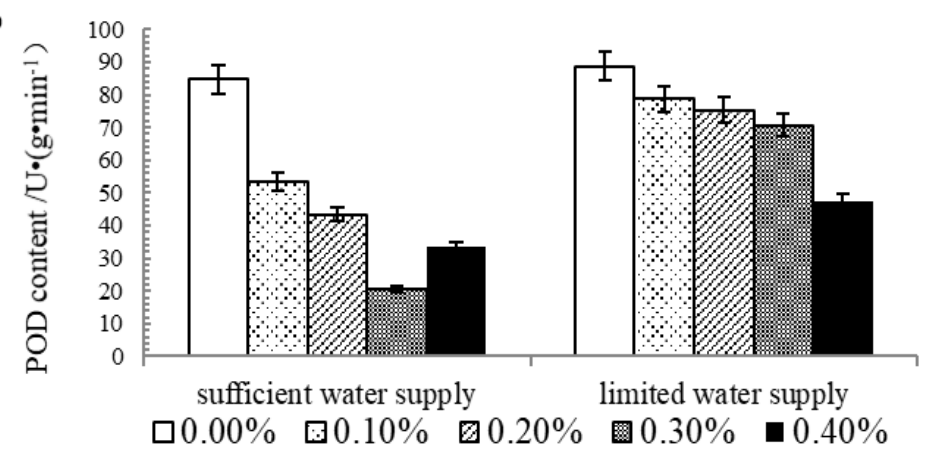

b: Effect of SAP on POD in C. dactylon leaves

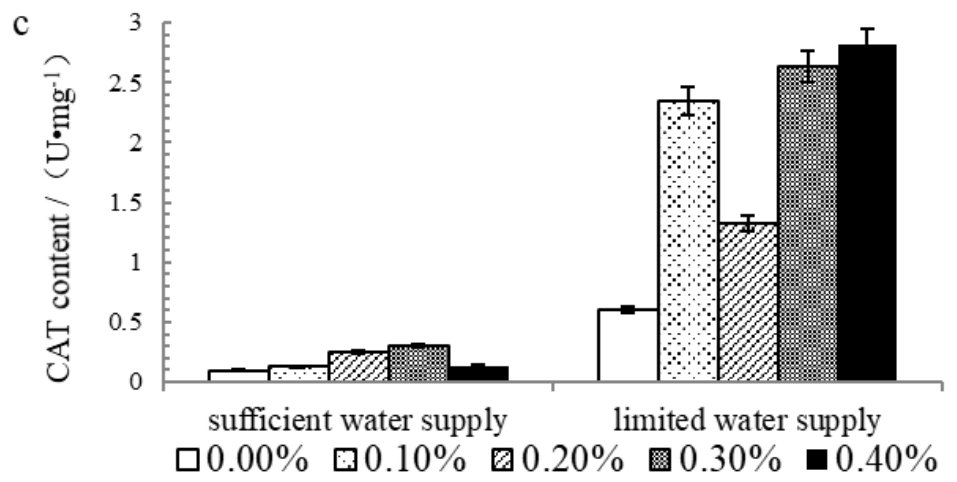

c: Effect of SAP on CAT in C. dactylon leaves

Figure 1. Effects of different SAP concentrations on C. dactylon leaf enzyme activity

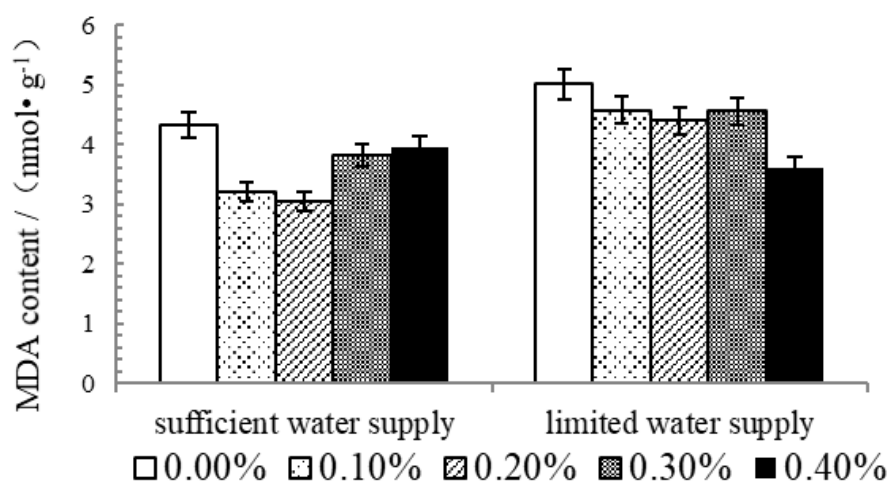

Figure 2. Effect of different SAP concentrations on MDA in C. dactylon leaves

APPLIED ECOLOGY AND ENVIRONMENTAL RESEARCH 18(3):4075-4085.

http://www.aloki.hu • ISSN 15891623 (Print) • ISSN 17850037 (Online)

DOI: http://dx.doi.org/10.15666/aeer/1803_40754085

(c) 2020, ALÖKI Kft., Budapest, Hungary 


\section{Effects of different SAP concentrations on drought resistance of C. dactylon seedlings}

Under water stress conditions, different concentrations of SAP will influence plant morphology and physiology variably, in addition to the effects of interactions and influence of various indices. The fuzzy membership function method could simplify the interrelationships among various indices, reveal the linkages among the indices of drought resistance, avoid the one-sidedness associated with the single index, and evaluate the drought resistance of plants more comprehensively (Wang et al., 2013). The analysis of fuzzy membership function of drought resistance of $C$. dactylon was based on the analysis of 9 indices, including Chl-a, Chl-b, Chl a+b, Car, Chl a/b, SOD, POD, CAT, and MDA. To evaluate the drought resistance of $C$. dactylon under the different SAP concentrations, the comprehensive evaluation value was calculated. According to the results, adding SAP could improve the drought resistance of $C$. dactylon seedlings. In addition, under adequate water conditions, the optimal SAP concentrations for the growth of $C$. dactylon based on their impacts on drought resistance in the species would be in the order of $0.30 \%>0.10 \%>0.20 \%>0.40 \%>0.00 \%$. Conversely, under limited water conditions, the order would be $0.20 \%>0.30 \%>0.40 \%>0.10 \%>0.00 \%$ (Table $2 \& 3$ ).

Table 2. The membership function and comprehensive evaluation of drought tolerance index for sufficient water supply of $C$. dactylon seedlings

\begin{tabular}{c|c|c|c|c|c|c}
\hline \multirow{2}{*}{ Determination index } & \multicolumn{5}{|c|}{ Treatment } & \multirow{2}{*}{ Weight } \\
\cline { 2 - 6 } & $\mathbf{C K}$ & $\mathbf{0 . 1 0 \%}$ & $\mathbf{0 . 2 0 \%}$ & $\mathbf{0 . 3 0 \%}$ & $\mathbf{0 . 4 0 \%}$ & \\
\hline Chl-a & 0.000 & 0.924 & 0.630 & 1.000 & 0.720 & 0.356 \\
Chl-b & 0.000 & 0.886 & 0.418 & 1.000 & 0.431 & 0.356 \\
Chl a+b & 0.000 & 0.914 & 0.572 & 1.000 & 0.642 & 0.356 \\
SOD & 0.000 & 0.877 & 0.726 & 1.000 & 0.651 & 0.356 \\
POD & 0.000 & 0.49 & 0.646 & 1.000 & 0.802 & 0.356 \\
Car & 0.000 & 0.496 & 0.690 & 0.547 & 1.000 & 0.291 \\
Chl a/b & 0.000 & 0.382 & 0.771 & 0.312 & 1.000 & 0.291 \\
CAT & 0.000 & 0.146 & 0.790 & 1.000 & 0.185 & 0.199 \\
MDA & 0.024 & 0.462 & 1.000 & 0.209 & 0.000 & 0.154 \\
Order & 0.004 & 1.812 & 1.802 & 2.261 & 1.774 & \\
Comprehensive evaluation value & 5 & 2 & 3 & 1 & 4 & \\
\hline
\end{tabular}

\section{Discussion}

\section{Response of photosynthetic pigments of C. dactylon seedlings to different SAP concentrations}

When plants are under water stress, the cell membrane system will be impaired, which would lead to the damage of the chloroplast ultrastructure and chlorophyll degradation, in addition to a decrease in chlorophyll concentration (Manuchehri and Salehi, 2014). According to the results of the present study, the concentrations of photosynthetic pigments in $C$. dactylon seedlings, including Chl-a, Chl-b, and $\mathrm{Chl} \mathrm{a}+\mathrm{b}$, were all higher than the concentrations in the CK when the SAPs with $0.10 \%-0.30 \%$ concentrations were applied under the two moisture conditions. The results indicated that in the process of SAP regulating soil water, and in turn plant growth, soil water content was not lower than 
the plant stress threshold, so that the chlorophyll concentration was not affected, and over time, SAP could enhance plant chlorophyll concentration indirectly to ensure that plants exploit the available light energy efficiently (Khadem et al., 2010). Similarly, the present study revealed that applying SAP could improve the concentrations of Car and chlorophyll a/b in $C$. dactylon. The increase in Car concentrations in could facilitate $C$. dactylon to tolerate stress induced by the production of lipid peroxides by membrane lipids (Jia et al., 2009). Zhang and Tan (2001) also suggested that drought resistance in species could be assessed based on a decrease in the $\mathrm{Chl}$ a/b ratio (Zhang and Tan, 2001). In the present study, the $\mathrm{Chl} \mathrm{a} / \mathrm{b}$ ratio in each SAP group was higher than in the $\mathrm{CK}$ group, and the variations were relatively low, which indicated that SAP application could promote $C$. dactylon seedling growth.

Table 3. The membership function and comprehensive evaluation of drought tolerance index for limited water supply of $C$. dactylon seedlings

\begin{tabular}{c|c|c|c|c|c|c}
\hline \multirow{2}{*}{ Determination index } & \multicolumn{5}{|c|}{ Treatment } & \multirow{2}{*}{ Weight } \\
\cline { 2 - 6 } & $\mathbf{C K}$ & $\mathbf{0 . 1 0 \%}$ & $\mathbf{0 . 2 0 \%}$ & $\mathbf{0 . 3 0 \%}$ & $\mathbf{0 . 4 0 \%}$ & \\
\hline Chl a/b & 0.000 & 0.23 & 0.768 & 1.000 & 0.69 & 0.364 \\
MDA & 0.000 & 0.316 & 0.441 & 0.324 & 1.000 & 0.364 \\
SOD & 0.000 & 0.110 & 0.746 & 0.929 & 1.000 & 0.364 \\
POD & 0.000 & 0.242 & 0.323 & 0.435 & 1.000 & 0.364 \\
Chl-a & 0.149 & 0.695 & 1.000 & 0.631 & 0.000 & 0.282 \\
Chl-b & 0.42 & 0.912 & 1.000 & 0.53 & 0.000 & 0.282 \\
Chl a+b & 0.223 & 0.754 & 1.000 & 0.603 & 0.000 & 0.282 \\
Car & 0.000 & 0.812 & 0.819 & 1.000 & 0.419 & 0.282 \\
CAT & 0.000 & 0.787 & 0.328 & 0.918 & 1.000 & 0.163 \\
Crder & 0.022 & 0.151 & 0.205 & 0.195 & 0.191 & \\
Comprehensive evaluation value & 5 & 4 & 1 & 2 & 3 & \\
\hline
\end{tabular}

\section{Responses of C. dactylon antioxidant enzymes to different SAP concentrations}

Under normal conditions, plants can eliminate the generated free radicals $\left(\mathrm{O}^{2-}\right)$ through their free radical-clearing systems, so that the production and elimination of reactive oxygen species in tissues are maintained at equilibrium states (Peng et al., 2002). When the equilibrium is lost, excess free radicals could trigger membrane lipid peroxidation and cause cell membrane system damage (Porcel et al., 2003). In the present study, the activities of membrane lipid peroxidation products, MDA, and protective enzymes, SOD, POD, and CAT, in C. dactylon, all changed following treatment with SAP under the two moisture conditions. The results showed that the SOD and POD activities in $C$. dactylon leaves treated with the SAP were lower than those in the CK, while CAT activity was higher than that in the CK. In addition, the MDA concentrations were also lower than in the CK. The reasons for the changes above could be as follows. Under the limited water supply condition, the SAP could reduce soil drought by regulating soil moisture availability, which is beneficial to the synergistic effects of SOD, POD, and CAT in $C$. dactylon leaves, to ensure that the free radicals are maintained at low levels to minimize the damage to the plant leaf membrane systems, similar to the production of lipid peroxidation product (MDA) to minimize the damage caused by drought on plants (Dacosta and Huang, 2007; Reddy et al., 2008). However, under adequate water conditions, sufficient water also led to shifts in the protective enzyme activities of 
seedlings, potentially due to the ability of SAP to absorb water and decrease the rate of evaporation of soil moisture, in turn, increasing the soil moisture concentrations under the adequate water supply condition, leading to a reduction in soil permeability, a decrease in nutrient-supply capacity, an increase in osmotic adjustment in leaves of seedlings, and eventually an increase in the concentrations of osmoregulation substances, and changes in protective enzyme activity and the lipid peroxidation products of leaves of seedlings leaves, as reported by Yang (2017).

\section{C. dactylon drought resistance under different SAP concentrations}

Under water stress, different SAP concentrations will influence plant morphology and physiology differently. This is consistent with the research on Wheat (Triticum aestivum L.) seedling conducted by Guan and Wu (2010). In addition, the indicators would interact and influence each other. A single drought resistance index may not comprehensively reflect the capacity of a plant to adapt to drought conditions (Wang et al., 2011). However, the values obtained from membership function analysis are average values, which could address the shortcomings of evaluations based on a few indicators. In addition, since the averages are whole numbers, the drought resistance indices become comparable. In the present study, under adequate water conditions, the five SAP concentrations were appropriate for $C$. dactylon seedlings in the order of $0.30 \%>0.10 \%>0.20 \%>0.40 \%>0.00 \%$. Conversely, under limited water availability conditions, the order was $0.20 \%>0.30 \%>0.40 \%>0.10 \%>0.00 \%$. The findings demonstrate that adding SAP could improve $C$. dactylon seedling drought resistance and are consistent with the results of previous studies where the addition of SAP to soil enhanced plant drought resistance (Qados, 2015; Yang et al., 2017).

\section{Conclusion}

In summary, the addition of SAP under different water conditions could improve the drought resistance of $C$. dactylon seedlings. The optimal SAP concentration was $0.30 \%$ under the adequate water conditions, and $0.20 \%$ under the limited water conditions. Therefore, in different areas where $C$. dactylon is adopted for greening, water conservation efforts should consider the $0.20-0.30 \%$ SAP concentration range for SAPs, which is conducive for the establishment of lawn and would extend the lawn irrigation time. In the present study, we investigated the effects of SAP on the physiological characteristics and drought resistance of $C$. dactylon seedlings under different water availability status. The effect of SAP on the entire life cycle of $C$. dactylon requires further investigation.

Acknowledgements. This research was supported by the Natural Scientific Foundation of China (41361017), the Natural Scientific Foundation of Jiangxi Province (20181BAB203021).

\section{REFERENCES}

[1] Qados, A. M. S. A. (2015): Effects of super absorbent polymer and Azotobacter vinelandii on growth and survival of Ficus benjamina L. seedlings under drought stress conditions. - International Research Journal of Agricultural Science and Soil Science 5(2): 45-57. 
[2] Arbona, V., Iglesias, D. J., Jacas, J., Primo-Millo, E., Talon, M. (2005): Hydrogel substrate amendment alleviates drought effects on young citrus plants. - Plant and Soil 270(1): 73-82.

[3] Archer, M. J. G., Caldwell, R. A. (2004): Response of Six Australian Plant Species to Heavy Metal Contamination at An Abandoned Mine Site. - Water Air Soil Pollution 157: 257-267.

[4] Dacosta, M., Huang, B. (2007): Changes in Antioxidant Enzyme Activities and Lipid Peroxidation for Bentgrass Species in Response to Drought Stress - Journal of the American Society for Horticultural Science 132(3): 319-326.

[5] Fernando, T. N., Ariaduraai, S. A., Disanayaka, C. K., Kulathunge, S., Aruggoda, A. G. B. (2017): Development of radiation grafted super absorbent polymers for agricultural applications. - Energy Procedia 127: 163-177.

[6] Guan, X. J., Wu, J. C. (2010): Effect of super absorbent polymers on physiological characteristics of wheat seedling under different soil moisture level. - Journal of Henan Agricultural Sciences 39(08): 28-32.

[7] Hameed, M., Ashraf, M. (2008): Physiological and biochemical adaptations of Cynodon dactylon (L.) Pers. from the Salt Range (Pakistan) to salinity stress. - Flora 203(8): 683694.

[8] Hu, H., Cao, Y., Yang, Y. (2014): Effects of soil moisture content on stolons germination and seedling growth of Cynodon dactylon. - Research of Soil and Water Conservation 21(3): $284-287+292$.

[9] Islam, M. R., Hu, Y. G., Mao, S. S., Mao, J. Z., Eneji, A. E., Xue, X. Z. (2011): Effectiveness of a water-saving super-absorbent polymer in soil water conservation for corn (Zea mays L.) based on eco-physiological parameters. - Journal of the Science of Food and Agriculture 11: 1998-2005.

[10] Jayanthi, J., Jalal, J. S., Lakshminarasimhan, P. (2016): Wild grasses and legumes of the Great Indian Bustard Wildlife Sanctuary, Maharashtra. - Ela Journal of Forestry and Wildlife 5(2): 183-191.

[11] Jia, G. M., Zhang, H. Y., Han, J. C., Huang, Y. P. (2009): Effects of soil water contents on the ecophysiological characteristics of Bermuda grass leaves. - Research of Soil and Water Conservation 16(05): 199-202.

[12] Karimi, A., Noshadi, M., Ahmadzadeh, M. (2009): Effects of Super Absorbent Polymer (Igeta) on Crop, Soil Water and Irrigation Interval. - Journal of Science and Technology of Agriculture and Natural Resources 12(46), 403-414.

[13] Khadem, S. A., Galavi, M., Ramrodi, M., Mousavi, S. R., Rousta, M. J., Parviz, R. M. (2010): Effect of animal manure and superabsorbent polymer on corn leaf relative water content, cell membrane stability and leaf chlorophyll content under dry condition. Australian Journal of Crop Science 4(08): 642-647.

[14] Kim, C., Lemke, C., Paterson, A. H. (2009): Functional dissection of drought-responsive gene expression patterns in Cynodon dactylon L. - Plant Molecular Biology 70: 1-16.

[15] Leung, A. K., Garg, A., Coo, J. L., Ng, C. W. W., Hau, B. C. H. (2015): Effects of the roots of Cynodon dactylon and Schefflera heptaphylla on water infiltration rate and soil hydraulic conductivity. - Hydrological Processes 29(15): 3342-3354.

[16] Li, L. B., Zhang, H. M., Zhou, X. M., Chen, M. X., Lu, L. C., Cheng, X. (2019): Effects of super absorbent polymer on scouring resistance and water retention performance of soil for growing plants in ecological concrete. - Ecological Engineering 138: 237-247.

[17] Manuchehri, R., Salehi, H. (2014): Physiological and biochemical changes of common bermudagrass (Cynodon dactylon, [L.] Pers.) under combined salinity and deficit irrigation stresses. - South African Journal of Botany 92: 83-88.

[18] Peng, L. X., Li, D. Q., Shu, H. R. (2002): Progress in water stress physiology and drought tolerance mechanism of horticultural plant. - Acta Botanica Boreali-Occidentalia Sinica 22(05): 1275-1281. 
[19] Porcel, R., Barea, J. M., Ruiz-Lozano, J. M. (2003): Antioxidant activities in mycorrhizal soybean plants under drought stress and their possible relationship to the process of nodule senescence. - New Phytologist 157: 135-143.

[20] Reddy, P. C. O., Sairanganayakulu, G., Thippeswamy, M., Thippeswamy, M., Sudhakar Reddy, P., Reddy, M. K., Chinta, S. (2008): Identification of stress-induced genes from the drought tolerant semi-arid legume crop horsegram (Macrotyloma uniflorum, (Lam.) Verdc.) through analysis of subtracted expressed sequence tags. - Plant Science 175(3): 372-384.

[21] Singh, K., Pande, V. C., Singh, R. P. (2013): Cynodon dactylon: An efficient perennial grass to revegetate sodic lands. - Ecological Engineering 54: 32-38.

[22] Srivastava, P., Singh, S. (2012): Conservation of soil, water and nutrients in surface runoff using riparian plant species. - Journal of Environmental Biology 33(1): 43-49.

[23] Suresh, R., Prasher, S. O., Patel, R. M., Qi, Z., Elsayed, E., Schwinghamer, T., Ehsan, A. M. (2018): Super Absorbent Polymer and Irrigation Regime Effects on Growth and Water Use Efficiency of Container-Grown Cherry Tomatoes. - the American Society of Agricultural and Biological Engineers 61(2): 523-531.

[24] Tongo, A., Mahdavi, A., Sayad, E. (2014): Effect of superabsorbent polymer Aquasorb on chlorophyll, antioxidant enzymes and some growth characteristics of Acacia victoria seedlings under drought stress. - Ecopersia 2(2): 571-583.

[25] Wang, T., Song, X., Yang, C. Z., Li, S., Xie, J. L. (2011): Remote sensing analysis on aeolian desertification trends in northern China during 1975-2010. - Journal of Desert Research 31(6): 1351-1356.

[26] Wang, X. K. (2006): Experimental Principles and Techniques of Plant Physiology and Biochemistry. - Higher Education Press, Beijing.

[27] Wang, Z. T., Ma, R., Ma, Y. J., Li, Y. (2013): The drought resistance of 5 species of Lespedeza. - Journal of Arid Land Resources and Environment 27(09): 119-123.

[28] Wu, Y., Sun, B. P., Zhang, J. F., Song, S. S., Shen, H. J., Chen, C., He, Y. (2018): Effects of water-retaining agent in different dosage on the growth and root morphology of 4 woody plants. - Science of Soil and Water Conservation 16(01): 96-102.

[29] Xie, Y., Fan, J. B., Zhu, W. X., Amombo, E., Lou, Y. H., Chen, L., Fu, J. M. (2016): Effect of heavy metals pollution on soil microbial diversity and bermudagrass genetic variation. - Frontiers in Plant Science 7: 755. https://doi.org/10.3389/fpls.2016.00755.

[30] Yang, J., Cao, Y., Wang, X. W., Huang, J. C., Li, S. (2017): Effect of super absorbent polymer on germination and physiological characteristics of Festuca arundinacea. Research of Soil and Water Conservation 24(1): 351-356.

[31] Yang, L. X., Yang, Y., Chen, Z., Guo, C. X., Li, S. C. (2014): Influence of super absorbent polymer on soil water retention, seed germination and plant survivals for rocky slope eco-engineering. - Ecological Engineering 62: 27-32.

[32] Zeng, L. S., Li, P. Y. (2019): Evaluation on drought resistance of 10 bermudagrass (Cynodon dactylon) germplasms from Xinjiang. - Chinese Journal of Grassland (03): 2229.

[33] Zhang, M. S., Tan, F. (2001): Relationship between ratio of chlorophyll a and b under water stress and drought resistance of different sweet potato varieties. - Seed 21(04): 2325.

[34] Zohuriaan-Mehr, M. J. A. D., Kabiri, K. (2008): Superabsorbent polymer materials: a review. - Iranian Polymer Journal 17(6): 451-477. 